\title{
TEORES DE MACRONUTRIENTES EM FOLHAS DE BANANEIRA CV. PACOVAN APODI, SOB LÂMINAS DE IRRIGAÇÃO E DOSES DE POTÁSSIO ${ }^{1}$
}

\section{ANDRÉIA DE A. F. BARROSO ${ }^{2}$, THALES V. DE A. VIANA ${ }^{3}$, ALBANISE B. MARINHO ${ }^{4}$, SOLERNE C. COSTA ${ }^{5}$, BENITO M. DE AZEVEDO ${ }^{6}$}

RESUMO: Por meio da análise química da folha, é possível avaliar o estado nutricional da planta, em que os resultados obtidos são comparados a padrões (correlação entre a concentração do nutriente nas folhas e o desenvolvimento da cultura). Objetivou-se, com este trabalho, avaliar as concentrações de macronutrientes nas folhas de bananeira sob lâminas de irrigação e doses de potássio na chapada do Apodi, Ceará. Utilizou-se o delineamento experimental em blocos casualizados, com arranjo em parcelas subdivididas, com três repetições. Foram empregadas cinco lâminas de irrigação (na parcela): $50 \%, 75 \%, 100 \%, 125 \%$ e $150 \%$ da ETc do lisímetro e quatro doses de potássio (na subparcela): $0 \%, 60 \%, 140 \%$ e $200 \%$ de $\mathrm{K}_{2} \mathrm{O}$ (recomendada pela análise do solo). As variáveis analisadas foram: N, P, K, Ca, Mg e S. Através do software "SAEG 9.0-UFV", os dados foram submetidos à análise de variância e, posteriormente, quando significativo pelo teste $\mathrm{F}$, a $5 \%$ de probabilidade, à análise de regressão. As lâminas de irrigação influenciaram significativamente $(\mathrm{p}<0,05)$ nos teores de $\mathrm{Ca}$ e $\mathrm{Mg}$, e a adubação potássica influenciou apenas nos teores de $\mathrm{K}, \mathrm{Mg}$ e $\mathrm{S}$.

PALAVRAS-CHAVE: Musa spp., análise foliar, manejo da irrigação.

\section{MACRONUTRIENT COMPOSITION IN BANANA LEAVES CV. PACOVAN APODI, UNDER IRRIGATION LEVELS AND POTASSIUM DOSES}

\begin{abstract}
Through chemical analysis on the sheet, it is possible to assess the nutritional status of the plant, where the results are compared to standards (correlation between the concentration in the leaves and the development of the culture). The objective of this study was to evaluate the levels of nutrients in banana leaves under irrigation levels and potassium levels in Apodi plateau, Ceará. It was used a randomized block design with split plot arrangement with three replications. It was used five irrigation levels (in the plot): $50 \%, 75 \%, 100 \%, 125 \%$ and $150 \%$ of the lysimeter ETc and four doses of potassium (in the subplot): $0 \%, 60 \%, 140 \%$ and $200 \%$ of $\mathrm{K}_{2} \mathrm{O}$ (recommended by soil analysis). The variables analyzed were: $\mathrm{N}, \mathrm{P}, \mathrm{K}, \mathrm{Ca}, \mathrm{Mg}$ and $\mathrm{S}$. Through the software "SAEG 9.0UFV" the data were subjected to analysis of variance and then when significant by the F test at 5\% probability, to the regression analysis. The water depth influenced significantly $(\mathrm{p}<0.05)$ in $\mathrm{Ca}$ and $\mathrm{Mg}$, and $\mathrm{K}$ fertilization influenced only the contents of $\mathrm{K}, \mathrm{Mg}$ and $\mathrm{S}$.
\end{abstract}

KEYWORDS: Musa spp., foliar analysis, management of irrigation.

\footnotetext{
${ }^{1}$ Extraído da Dissertação do primeiro autor. Projeto financiado pelo CNPq.

${ }^{2}$ Tecnóloga em RH/Irrigação, M. Sc. em Engenharia Agrícola, Área de Concentração em Irrigação e Drenagem, IFCE - Câmpus Limoeiro do Norte, Fone: (0XX88) 9958.0528, andreiaafb@ gmail.com.

${ }^{3}$ Eng $^{\circ}$ Agrônomo, Prof. Dr., Departamento de Engenharia Agrícola, UFC, Fortaleza - CE, thales@ufc.br.

${ }^{4}$ Eng $^{\underline{a}}$ Agrícola, Dra., Pesquisadora PNPD/Capes/UFC, albanisebm@ gmail.com.

${ }^{5}$ Eng ${ }^{0}$ Agrônomo, Prof. Dr., Curso de Irrigação e Drenagem, IFCE - Câmpus Limoeiro do Norte - CE, solerne_1@ @hotmail.com.

${ }^{6}$ Eng $^{\mathrm{o}}$ Agrônomo, Prof. Dr., Departamento de Engenharia Agrícola, UFC, Fortaleza - CE, benito@ ufc.br.

Recebido pelo Conselho Editorial em: 28-10-2009

Aprovado pelo Conselho Editorial em: 13-4-2011
} 


\section{INTRODUÇÃO}

Dentre as atividades da fruticultura brasileira, o agronegócio da banana (Musa spp.) é um dos setores de maior potencial devido aos incentivos do governo e à excelente localização geográfica do País que proporciona boas condições climáticas, além de favoráveis características de solo e disponibilidade hídrica. Segundo o IBGE (2007), a produção brasileira de banana totalizou 7,01 milhões de toneladas de cachos, com uma área colhida de 513,50 mil hectares.

A fertirrigação é o processo de aplicação simultânea de água e fertilizantes às plantas, por meio de sistema de irrigação, trazendo como vantagens maior eficiência e economia de fertilizantes e mão de obra, aplicação da dose correta, na profundidade adequada, possibilidade de veiculação de diversos tipos de produtos, menor risco, maior facilidade de aplicação e versatilidade de uso em qualquer tipo de solo (KOETZ et al., 2006). A possibilidade da aplicação de adubo, principalmente nitrogênio e potássio, via fertirrigação, é outra vantagem, trazendo benefícios indiretos ao planejamento da cultura (DALRI \& CRUZ, 2008).

O potássio $(\mathrm{K})$ é o macronutriente absorvido em maior quantidade pela bananeira, tendo função direta nas trocas metabólicas, no transporte da seiva elaborada, na retenção de água e nas qualidades organolépticas do fruto (BRASIL et al., 2000). A participação do potássio na bananeira está mais diretamente associada à produção de cachos, pencas, produtividade, maior resistência pós-colheita e qualidade dos frutos. A bananeira exige elevadas quantidades de potássio para atingir níveis satisfatórios de produtividade (GUERRA et al., 2004).

A diagnose foliar de plantas frutíferas vem sendo usada para detectar respostas das plantas aos vários tipos de manejo, possibilitando interpretar, de maneira mais eficiente, as relações entre nutrientes na planta (SILVA \& CARVALHO, 2005).

Por meio da análise química dos nutrientes na folha, órgão que apresenta maior atividade fisiológica, avalia-se o estado nutricional da planta, comparando-se com um padrão. Para interpretação dos resultados obtidos, estabelecem-se teores-padrão ou faixas de referência, comparando-os com os valores já existentes, através da correlação entre a concentração do nutriente nas folhas e o desenvolvimento ou a produção da cultura. Os teores-padrão de referência têm aplicação universal, embora estejam sempre relacionados com fatores ambientais, solo, cultivares, etc. Assim, os valores de referência quase sempre precisam ser adaptados às condições locais, embora alguma extrapolação sempre seja possível (BATAGLIA \& DECHEN, 1986).

Em ordem decrescente, a bananeira absorve os macronutrientes: $\mathrm{K}>\mathrm{N}>\mathrm{Ca}>\mathrm{Mg}>\mathrm{S}>\mathrm{P}$. BORGES et al. (2000) relataram a exportação de $1,9 \mathrm{~kg}$ de $\mathrm{N} ; 0,23 \mathrm{~kg}$ de P; $5,2 \mathrm{~kg}$ de $\mathrm{K} ; 0,22 \mathrm{~kg}$ de $\mathrm{Ca}$ e $0,30 \mathrm{~kg}$ de $\mathrm{Mg} \mathrm{t}^{-1}$ de cachos produzidos. Para as condições do polo de irrigação PetrolinaPE/Juazeiro-BA, BORGES \& CALDAS (2003) encontraram os seguintes teores-padrão de nutrientes na folha definidos para a cultura da bananeira cv. Pacovan: $22-24 \mathrm{~g} \mathrm{de} \mathrm{N} \mathrm{kg}^{-1} ; 1,7-1,9 \mathrm{~g}$ de $\mathrm{P} \mathrm{kg}{ }^{-1}$; 25-28 g de $\mathrm{K} \mathrm{kg}^{-1}$; 6,3-7,3 $\mathrm{g} \mathrm{de} \mathrm{Ca} \mathrm{kg}^{-1}$; 3,1-3,5 g de $\mathrm{Mg} \mathrm{kg}^{-1}$ e 1,7-1,9 g de $\mathrm{S} \mathrm{kg}^{-1}$.

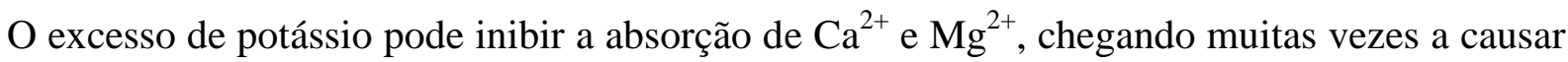
a deficiência desses dois nutrientes. Esse excesso tende a induzir alterações no peso do fruto e, consequentemente, efeitos depressivos na produtividade (SILVA \& MAROUELLI, 2002).

Segundo AQUINO (2003 b), doses excessivas de potássio podem acarretar, ainda, a lixiviação do cátion $\mathrm{K}^{+}$e provocar um efeito salino no solo.

Assim, o trabalho foi realizado com o objetivo de avaliar os teores dos macronutrientes em folhas de bananeira cv. Pacovan Apodi, no terceiro ciclo produtivo, sob lâminas de irrigação e doses de potássio nas condições edafoclimáticas da Chapada do Apodi, Ceará.

\section{MATERIAL E MÉTODOS}

O trabalho foi conduzido na área experimental da agroempresa FRUTACOR, na Chapada do

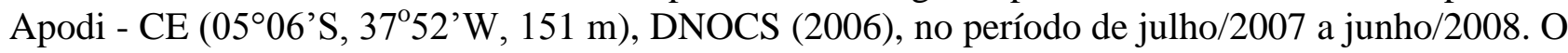


plantio foi realizado em sistema de fileiras duplas $(4,0 \mathrm{~m} \times 2,0 \mathrm{~m} \times 2,0 \mathrm{~m})$ e as adubações foram realizadas de acordo com a recomendação da análise de solo e os estádios de desenvolvimento da cultura. As características físico-químicas do solo da área experimental foram determinadas no Laboratório de Solos e Águas para Irrigação do CENTEC de Limoeiro do Norte, a partir de amostras coletadas em profundidades: 0-20 e 20-40 cm, Tabelas 1 e 2.

TABELA 1. Caracterização física do solo da área experimental: capacidade de campo (CC), ponto de murcha permanente (PMP), densidade global ( $\rho$ s) e teores de argila, silte e areia. Physical characterization of the experimental area: field capacity (CC), permanent wilting point (PMP), bulk density ( $\rho)$, and clay, silt and sand levels.

\begin{tabular}{|c|c|c|c|c|c|c|c|}
\hline Camadas & $\mathrm{CC}$ & PM & \multirow{2}{*}{$\begin{array}{c}\rho s \\
\mathrm{~g} \mathrm{~cm}^{-3}\end{array}$} & $\begin{array}{l}\text { Areia } \\
\text { grossa }\end{array}$ & Areia fina & Silte & Argila \\
\hline $\mathrm{cm}$ & \multicolumn{2}{|c|}{$\mathrm{g} 100 \mathrm{~g}^{-1}$} & & \multicolumn{4}{|c|}{$\mathrm{g} \mathrm{kg}^{-1}$} \\
\hline $0-20$ & 22,6 & 16,1 & 1,34 & 290 & 272 & 175 & 263 \\
\hline $20-40$ & 26,0 & 19,0 & 1,35 & 191 & 243 & 200 & 366 \\
\hline
\end{tabular}

Fonte: Laboratório de Solos e Água para Irrigação, CENTEC de Limoeiro do Norte - Ceará.

TABELA 2. Caracterização química do solo da área experimental antes do plantio, nas camadas de 0-20 e 20-40 cm, região da Chapada do Apodi, Limoeiro do Norte - Ceará. Chemical characterization of the experimental area before planting in layers from 0 - 20 and 20 - $40 \mathrm{~cm}$, in the Chapada do Apodi, Limoeiro do Norte - Ceará.

\begin{tabular}{ccccccccccccc}
\hline Prof. & $\mathrm{pH}$ & $\mathrm{MO}$ & $\mathrm{P}$ & $\mathrm{K}$ & $\mathrm{Ca}$ & $\mathrm{Mg}$ & $\mathrm{Na}$ & $\mathrm{H}+\mathrm{Al}$ & $\mathrm{SB}$ & $\mathrm{CTC}$ & $\mathrm{V}$ & \multicolumn{2}{c}{ PST } \\
\hline (cm) & & $\mathrm{g} \mathrm{kg}^{-1}$ & $\mathrm{mg} \mathrm{dm}^{-3}$ & \multicolumn{6}{c}{$\mathrm{mmol}_{\mathrm{c}} \mathrm{dm}^{-3}$} \\
\hline $0-20$ & 7,2 & 20,89 & 45 & 17,61 & 96,0 & 27,0 & 8,27 & 13,6 & 148,9 & 162,5 & 92 & 5 \\
$20-40$ & 7,3 & 12,62 & 13 & 6,81 & 79,0 & 11,0 & 5,59 & 22,3 & 102,4 & 124,7 & 82 & 4 \\
\hline
\end{tabular}

Fonte: Laboratório de Solos e Água para Irrigação, CENTEC de Limoeiro do Norte - Ceará.

A cultura utilizada foi a bananeira (Musa spp.), cujo material genético usado foi o SH3640 (Pacovan Apodi), um híbrido do subgrupo Prata-Anã, durante o terceiro ciclo de produção.

O sistema de irrigação utilizado foi por gotejamento, constando de cinco emissores por planta, com vazão nominal de $2,3 \mathrm{~L} \mathrm{~h}^{-1}$ e PS de 20 m.c.a. As lâminas aplicadas nos diferentes tratamentos foram controladas por meio de registros posicionados no início de cada linha lateral de gotejadores.

As lâminas diferenciadas foram baseadas na ETc do lisímetro de drenagem e aplicadas em função do tempo de irrigação [eq.(1)]. A lâmina total diária foi parcelada em duas aplicações por dia (manhã e tarde).

$$
\mathrm{Ti}=\frac{\operatorname{ETc} \operatorname{Ap} 60}{\mathrm{q} \text { ng ef }}
$$

em que,

Ti - tempo de irrigação, min;

ETc - evapotranspiração da cultura, mm;

Ap - área da planta $\left(6 \mathrm{~m}^{2}\right)$;

$\mathrm{Q}$ - vazão média dos gotejadores, $\mathrm{L} \mathrm{h}^{-1}$;

$\mathrm{Ng}$ - número de gotejadores planta ${ }^{-1}, \mathrm{e}$

Ef - eficiência do sistema de irrigação.

O delineamento experimental utilizado foi em blocos casualizados, com arranjo em parcelas subdivididas, com três repetições. Foram empregadas cinco lâminas de irrigação (na parcela): 50\%, $75 \%, 100 \%, 125 \%$ e $150 \%$ da ETc do lisímetro de drenagem, que corresponde a $\mathrm{L}_{1}, \mathrm{~L}_{2}, \mathrm{~L}_{3}, \mathrm{~L}_{4}$ e $\mathrm{L}_{5}$, respectivamente, e quatro doses de potássio (na subparcela): $0 \%, 60 \%, 140 \%$ e $200 \%$ de $\mathrm{K}_{2} \mathrm{O}$ 
(recomendada pela análise do solo), que corresponde a $\mathrm{K}_{1}, \mathrm{~K}_{2}, \mathrm{~K}_{3} \mathrm{e} \mathrm{K}_{4}$, respectivamente. A fonte de potássio utilizada foi o Cloreto de Potássio.

De cada tratamento e repetição, coletaram-se aleatoriamente amostras da terceira folha verdadeira a partir do ápice da planta. Desta folha, retiraram-se de 10 a $15 \mathrm{~cm}$ da parte interna mediana do limbo, eliminando-se a nervura central. Essas amostras de folhas foram analisadas para determinar os teores de $\mathrm{N}, \mathrm{P}, \mathrm{K}, \mathrm{Ca}, \mathrm{Mg}$ e $\mathrm{S}$, de acordo com o método proposto por SILVA \& RODRIGUES (2001). Após este procedimento, o material foi levado ao laboratório, onde as amostras foram lavadas, secadas em estufa a $60^{\circ} \mathrm{C}$ e trituradas em moinho até a obtenção de um pó, para posteriormente realizar as devidas análises.

Os resultados obtidos foram submetidos à análise de variância, utilizando-se do valor máximo de $5 \%$ de probabilidade, pelo teste $\mathrm{F}$, e quando significativos, realizou-se a análise de regressão, selecionando-se o modelo que apresentou melhores níveis de significância e coeficiente de determinação $\left(\mathrm{R}^{2}\right)$. As análises foram realizadas através do software "SAEG/UFV 9.0".

\section{RESULTADOS E DISCUSSÃO}

Durante o terceiro ciclo da cultura da bananeira cv. Pacovan Apodi, as lâminas de irrigação aplicadas foram $691 ; 1.036 ; 1.381 ; 1.726$ e $2.072 \mathrm{~mm} \mathrm{ciclo}^{-1}$ referentes a $50 ; 75 ; 100 ; 125$ e $150 \%$ da ETc, respectivamente. Os totais mensais de precipitação variaram de 0,00 a 178,69 mm, totalizando em $342,44 \mathrm{~mm}$ para o período, sendo as maiores precipitações ocorridas nos meses de janeiro e março. Os totais de $\mathrm{K}_{2} \mathrm{O}$ aplicados durante o terceiro ciclo foram: $\mathrm{K}_{1}=0 \mathrm{~g}$ planta $^{-1} ; \mathrm{K}_{2}=$ $254 \mathrm{~g}$ planta $^{-1} ; \mathrm{K}_{3}=592 \mathrm{~g} \mathrm{planta}^{-1}$; e $\mathrm{K}_{4}=850 \mathrm{~g} \mathrm{planta}^{-1}$.

A análise de variância mostrou que os teores de $\mathrm{N}, \mathrm{P}, \mathrm{K}$ e $\mathrm{S}$ não foram influenciados pelas lâminas de irrigação aplicadas ao nível de 5\% de probabilidade, pelo teste $\mathrm{F}$, obtendo-se efeito significativo apenas para as concentrações de $\mathrm{Ca}$ e $\mathrm{Mg}$. A adubação potássica influenciou significativamente nos teores de $\mathrm{K}, \mathrm{Mg}$ e $\mathrm{S}$, não havendo diferença nos demais nutrientes analisados. Quanto à interação entre as lâminas de irrigação e as doses de potássio, verificou-se efeito significativo apenas para os teores de $\mathrm{K}$ e $\mathrm{S}$ (Tabela 3).

Os teores médios de $\mathrm{N}$ e $\mathrm{P}$ na folha foram de 22; 77 e $1,77 \mathrm{~g} \mathrm{~kg}^{-1}$, respectivamente, que de acordo com BORGES \& CALDAS (2003) estão dentro da faixa adequada para a cultura, que é de 20-22 $\mathrm{g} \mathrm{kg}^{-1}$ de $\mathrm{N}$ e de $1,7-1,9 \mathrm{~g} \mathrm{~kg}^{-1}$ de P.

TABELA 3. Resumo da análise de variância do N, P, K, Ca, Mg e S, na folha de bananeira cv. Pacovan Apodi, sob as lâminas de irrigação e doses de potássio, na região da Chapada do Apodi, Limoeiro do Norte - Ceará, 2008. Summary of the analysis of variance of N, P, K, Ca, Mg and S, from the banana leaf cv. Pacovan Apodi, under the irrigation levels and potassium doses in the Chapada do Apodi, Limoeiro do Norte - Ceará, 2008.

\begin{tabular}{|c|c|c|c|c|c|c|c|}
\hline \multirow{2}{*}{$\begin{array}{l}\text { Fonte de } \\
\text { Variação }\end{array}$} & \multirow{2}{*}{ GL } & \multicolumn{6}{|c|}{ Quadrado Médio (significância - Prob. >F) } \\
\hline & & $\mathrm{N}$ & $\mathrm{P}$ & $\mathrm{K}$ & $\mathrm{Ca}$ & $\mathrm{Mg}$ & $S$ \\
\hline Bloco & 2 & $10,416^{\mathrm{ns}}$ & $0,151^{\mathrm{ns}}$ & $8,619^{\mathrm{ns}}$ & $2,917 *$ & $0,0176^{\mathrm{ns}}$ & $0,0118^{\mathrm{ns}}$ \\
\hline Lâminas & 4 & $6,391^{\mathrm{ns}}$ & $0,287^{\mathrm{ns}}$ & $21,975^{\mathrm{ns}}$ & $10,233^{*}$ & $0,704 *$ & $0,0473^{\mathrm{ns}}$ \\
\hline Resíduo (a) & 8 & 6,586 & 0,399 & 9,169 & 0,835 & 0,223 & 0,0369 \\
\hline $\mathrm{K}_{2} \mathrm{O}$ & 3 & $2,952^{\mathrm{ns}}$ & $0,492^{\mathrm{ns}}$ & $74,559 *$ & $4,752^{\mathrm{ns}}$ & $2,063^{*}$ & $0,269 *$ \\
\hline Lam x $\mathrm{K}_{2} \mathrm{O}$ & 12 & $11,629^{\mathrm{ns}}$ & $0,278^{\mathrm{ns}}$ & $63,954 *$ & $3,241^{\mathrm{ns}}$ & $0,389^{\text {ns }}$ & $0,0671 *$ \\
\hline Resíduo (b) & 30 & 11,948 & 0,268 & 16,857 & 2,343 & 0,536 & 0,0281 \\
\hline Total & 59 & & & & & & \\
\hline Média & & 22,774 & 1,771 & 12,447 & 3,264 & 3,173 & 1,645 \\
\hline C.V. \% & & 15,178 & 29,214 & 32,987 & 26,902 & 23,070 & 10,186 \\
\hline
\end{tabular}

* Significativo a $5 \%$ de probabilidade, pelo teste F; ${ }^{\mathrm{ns}}$ não significativo a 5\% de probabilidade, pelo teste $\mathrm{F}$. 
A partir da análise de regressão, verificou-se que o teor de cálcio em função das lâminas de irrigação se ajustou a um modelo polinomial quadrático (Figura 1). Na lâmina máxima estimada de $1.333,33 \mathrm{~mm}$, o teor de $\mathrm{Ca}$ na folha foi de $2,52 \mathrm{~g} \mathrm{~kg}^{-1}$. Esse valor encontra-se abaixo do intervalo-padrão recomendado para essa cultura, que é de 6,3 - 7,3 $\mathrm{g} \mathrm{kg}^{-1}$ (BORGES \& CALDAS, 2003). Possivelmente, a concentração desse íon sofreu uma lixiviação no solo a partir da aplicação de lâminas acima de 1.333,33 mm, havendo uma diminuição no teor de Ca na folha. A deficiência desse íon provoca a redução da área foliar, ocasionando cloroses que evoluem para necroses em pontos isolados das folhas. Entretanto, sintomas de deficiência de Ca não foram observados nas folhas das bananeiras do terceiro ciclo.

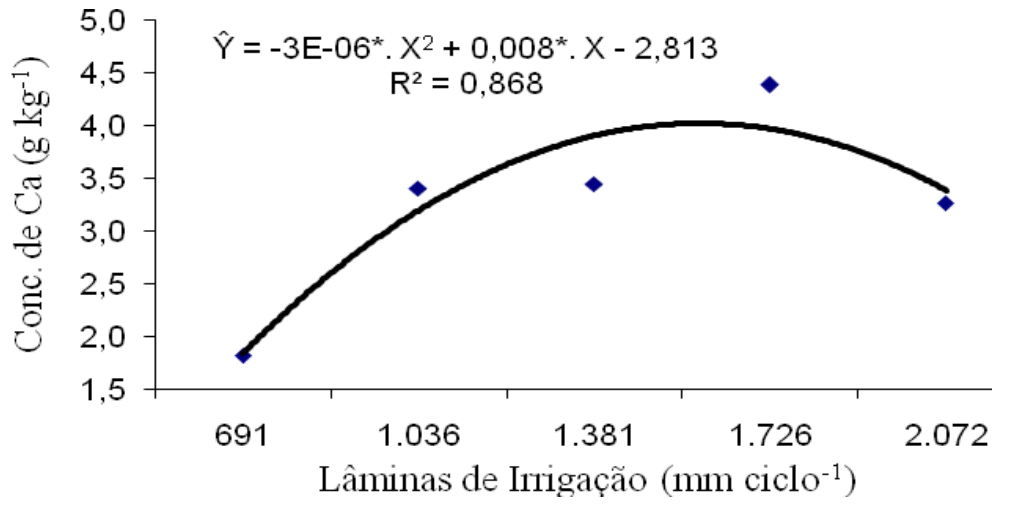

FIGURA 1. Concentração de Ca na folha de bananeira cv. Pacovan Apodi em função das lâminas de irrigação, região da Chapada do Apodi, Limoeiro do Norte - Ceará, 2008. Ca concentration in the banana leaf cv. Pacovan Apodi depending on the irrigation levels, in the Chapada do Apodi, Limoeiro do Norte - Ceará, 2008.

Valores médios da concentração de $\mathrm{Mg}$ na folha de bananeira para os diferentes tratamentos aplicados (Tabela 4) . Embora as lâminas de irrigação tenham influenciado nos resultados, não foi possível ajustar a um modelo matemático para relacionar os dois fatores. O máximo teor de $\mathrm{Mg}$ na folha foi de $4,10 \mathrm{~g} \mathrm{~kg}^{-1}$ obtido no tratamento $\mathrm{L}_{3} \mathrm{~K}_{1}$, e o menor teor foi de $2,20 \mathrm{~g} \mathrm{~kg}^{-1}$ no tratamento $\mathrm{L}_{3} \mathrm{~K}_{3}$. Esse valor encontra-se muito próximo dos padrões recomendados por BORGES \& CALDAS (2003) para a concentração de $\mathrm{Mg}$, que é de 3,1 - 3,5 $\mathrm{g} \mathrm{kg}^{-1}$.

TABELA 4. Valores médios da concentração de $\mathrm{Mg}\left(\mathrm{g} \mathrm{kg}^{-1}\right)$ na folha, para os diferentes tratamentos na cultura da bananeira cv. Pacovan Apodi, terceiro ciclo, região da Chapada do Apodi, Limoeiro do Norte - Ceará, 2008. Mean values of the concentration of $\mathrm{Mg}\left(\mathrm{g} \mathrm{kg}^{-1}\right)$ on the leaf, for the different treatments in the banana culture, cv. Pacovan Apodi, $3^{\circ}$ cycle, in the Chapada do Apodi, Limoeiro do Norte - Ceará, 2008.

\begin{tabular}{|c|c|c|c|c|c|c|}
\hline \multirow{2}{*}{$\begin{array}{l}\text { Doses de Potássio } \\
\left(\mathrm{g} \mathrm{planta}^{-1} \text { ciclo }^{-1}\right)\end{array}$} & \multicolumn{6}{|c|}{ Lâminas de Irrigação (mm planta ciclo $\left.{ }^{-1}\right)$} \\
\hline & $\mathrm{L}_{1}=691$ & $\mathrm{~L}_{2}=1.036$ & $\mathrm{~L}_{3}=1.381$ & $\mathrm{~L}_{4}=1.726$ & $\mathrm{~L}_{5}=2.072$ & Média \\
\hline $\mathrm{K}_{1}=0$ & 3,58 & 3,57 & 4,10 & 3,58 & 3,47 & 3,47 \\
\hline $\mathrm{K}_{2}=254$ & 3,12 & 3,12 & 3,27 & 3,75 & 3,02 & 3,02 \\
\hline$K_{3}=592$ & 3,10 & 2,68 & 2,20 & 3,92 & 2,88 & 2,88 \\
\hline $\mathrm{K}_{4}=850$ & 2,72 & 2,42 & 3,10 & 3,07 & 2,82 & 2,82 \\
\hline Média & 3,13 & 2,95 & 3,17 & 3,58 & 3,05 & 3,05 \\
\hline
\end{tabular}

A partir da análise de regressão, verificou-se que o modelo linear foi o que melhor se ajustou para relacionar a concentração de $\mathrm{Mg}$ na folha, na função das doses de potássio, obtendo-se um coeficiente de determinação $\mathrm{R}^{2}$ de 0,952 (Figura 2). Observou-se que a concentração de $\mathrm{Mg}$ na 
folha decresceu linearmente com o aumento da dose de potássio. A equação linear decrescente explica o antagonismo do $\mathrm{K}$ em relação ao magnésio, ou seja, a concentração de $\mathrm{Mg}$ decresceu linearmente com o aumento das doses de potássio, e o tratamento sem a aplicação de potássio proporcionou a maior concentração desse elemento na folha. O desbalanço entre potássio $(\mathrm{K})$ e magnésio ( $\mathrm{Mg}$ ) é um problema que pode ocorrer com frequência na cultura da bananeira, ocasionando o "azul da bananeira" um distúrbio fisiológico (EMBRAPA, 2004).

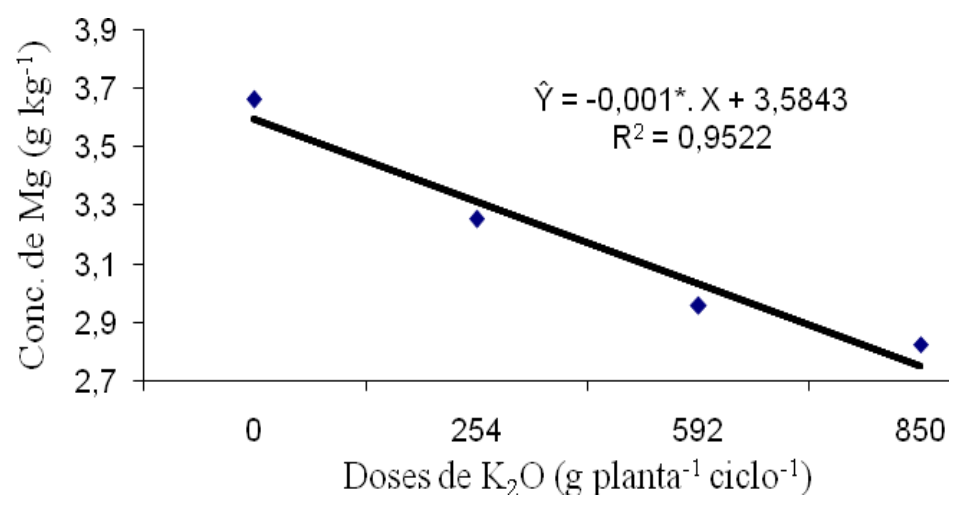

FIGURA 2. Concentração de Mg na folha para as doses de potássio na cultura da bananeira cv. Pacovan Apodi terceiro ciclo, na região da Chapada do Apodi, Limoeiro do Norte Ceará, 2008. Mg concentration in the leaf to the potassium in the banana culture, cv. Pacovan Apodi $3^{\circ}$ cycle, in the Chapada do Apodi, Limoeiro do Norte - Ceará, 2008.

Valores médios de $\mathrm{S}$ na folha de bananeira em função das lâminas de irrigação e doses de potássio (Tabela 5). Embora as doses de potássio tenham influenciado significativamente no teor de $\mathrm{S}$, não foi possível estabelecer uma relação funcional para essa variável.

TABELA 5. Valores médios da concentração de $\mathrm{S}\left(\mathrm{g} \mathrm{kg}^{-1}\right)$ na folha, para os tratamentos aplicados na cultura da bananeira cv. Pacovan Apodi, terceiro ciclo, na região da Chapada do Apodi, Limoeiro do Norte - Ceará, 2008. Mean values for the $\mathbf{S}$ concentration (g kg) on the leaf, for the different treatments applied in the banana culture, cv. Pacovan Apodi, $3^{\circ}$ cycle, in the Chapada do Apodi, Limoeiro do Norte - Ceará, 2008.

\begin{tabular}{ccccccc}
\hline \multirow{2}{*}{$\begin{array}{c}\text { Níveis de Potássio } \\
\left(\text { g planta }^{-1} \text { ciclo }^{-1}\right)\end{array}$} & \multicolumn{5}{c}{ Lâminas de Irrigação (mm planta dia $\left.{ }^{-1}\right)$} \\
\cline { 2 - 6 } & $\mathrm{L}_{1}=691$ & $\mathrm{~L}_{2}=1.036$ & $\mathrm{~L}_{3}=1.381$ & $\mathrm{~L}_{4}=1.726$ & $\mathrm{~L}_{5}=2.072$ & Média \\
\hline $\mathrm{K}_{1}=0$ & 1,47 & 1,56 & 1,95 & 1,48 & 1,50 & 1,59 \\
$\mathrm{~K}_{2}=254$ & 1,72 & 1,79 & 1,86 & 1,51 & 1,87 & 1,75 \\
$\mathrm{~K}_{3}=592$ & 1,43 & 1,42 & 1,55 & 1,53 & 1,46 & 1,48 \\
$\mathrm{~K}_{4}=850$ & 1,43 & 1,89 & 1,61 & 1,89 & 1,67 & 1,70 \\
\hline Média & 1,52 & 1,67 & 1,74 & 1,60 & 1,63 & 1,63 \\
\hline
\end{tabular}

Analisando a combinação da lâmina aplicada com as doses de potássio, verificou-se que a maior concentração de $\mathrm{S}$ ocorreu no tratamento $\mathrm{L}_{3} \mathrm{~K}_{1}$, com valor de $1,95 \mathrm{~g} \mathrm{~kg}^{-1}$ de $\mathrm{S}$. Esse nutriente teve o comportamento semelhante ao do $\mathrm{Mg}$, obtendo valor máximo na lâmina do produtor $\left(\mathrm{L}_{3}=\right.$ $100 \%$ ETc) e sem a aplicação de potássio $\left(\mathrm{K}_{1}\right)$.

A concentração média de $S$ na folha foi de $1,63 \mathrm{~g} \mathrm{~kg}^{-1}$ em que esse valor se encontra abaixo do intervalo-padrão recomendado para essa cultura, de 1,7 - 1,9 $\mathrm{g} \mathrm{kg}^{-1}$ (BORGES \& CALDAS, 2003). 
A análise de variância mostrou que, para o terceiro ciclo da cultura, as lâminas de irrigação não influenciaram estatisticamente na concentração de K na folha. COSTA (2009), estudando o efeito de cinco lâminas de irrigação no primeiro e segundo ciclos da cv. Pacovan Apodi, na região da Chapada do Apodi, só encontrou influência significativa para o $1^{\circ}$ ciclo. Possivelmente, a não resposta para os demais ciclos seria devido ao bananal não estar totalmente estabelecido no campo.

A partir da análise de regressão, mostrou que a concentração de potássio na folha cresceu linearmente com o aumento das doses de $\mathrm{K}_{2} \mathrm{O}$, e quanto maior for a aplicação de potássio, maior será a concentração do mesmo na folha (Figura 3). Esses resultados justificam o antagonismo mostrado na concentração de $\mathrm{Mg}$ na folha da bananeira (Figura 2), pois quando o K está elevado, a concentração de $\mathrm{Mg}$ está baixa, e vice-versa, resultando em equações lineares crescentes e decrescentes para $\mathrm{K} \mathrm{e} \mathrm{Mg}$, respectivamente.

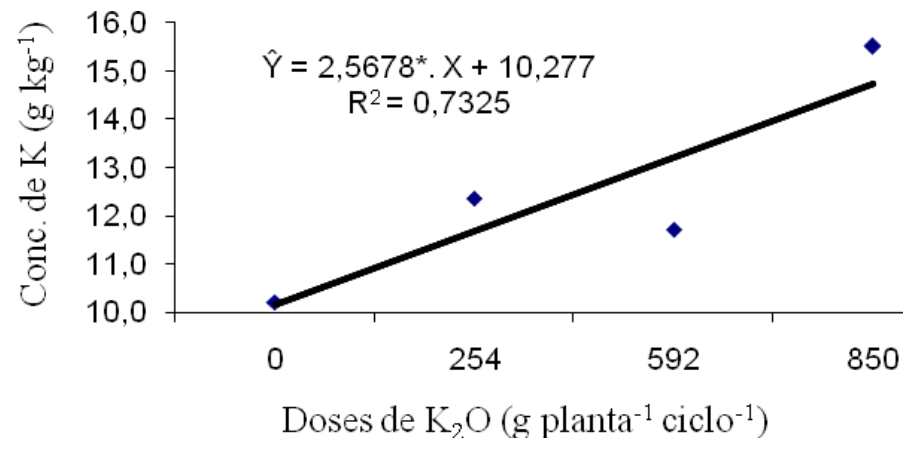

FIGURA 3. Concentração de $\mathrm{K}$ na folha para as doses de potássio na cultura da bananeira cv. Pacovan Apodi, terceiro ciclo, na região da Chapada do Apodi, Limoeiro do Norte Ceará, 2008. $K$ concentration in the leaf to the potassium doses in the banana culture, cv. Pacovan Apodi, $3^{\circ}$ cycle, in the Chapada Apodi, Limoeiro do Norte Ceará, 2008.

Teores médios de $\mathrm{K}$ na folha para os diferentes tratamentos aplicados na cultura da bananeira cv. Pacovan Apodi, terceiro ciclo, na região da Chapada do Apodi, Limoeiro do Norte Ceará, 2008 (Tabela 6).

TABELA 6. Valores médios da concentração de $\mathrm{K}\left(\mathrm{g} \mathrm{kg}^{-1}\right)$ na folha, para os tratamentos aplicados na cultura da bananeira cv. Pacovan Apodi, terceiro ciclo, na região da Chapada do Apodi, Limoeiro do Norte - Ceará, 2008. Mean values of $K$ content (g kg-1) on the leaf, for the different treatments applied in the banana culture, cv. Pacovan Apodi, $3^{\circ}$ cycle, in the Chapada Apodi, Limoeiro do Norte - Ceará, 2008.

\begin{tabular}{crrrrrl}
\hline Níveis de Potássio & \multicolumn{7}{c}{ Lâminas de Irrigação } \\
\cline { 2 - 7 }$\left(\right.$ g planta $^{-1}$ ciclo $\left.^{-1}\right)$ & \multicolumn{1}{c}{$\mathrm{L}_{1}$} & \multicolumn{1}{c}{$\mathrm{L}_{2}$} & $\mathrm{~L}_{3}$ & \multicolumn{1}{c}{$\mathrm{L}_{4}$} & \multicolumn{1}{c}{$\mathrm{L}_{5}$} & Média \\
\hline $\mathrm{K}_{1}=0$ & 10,16 & 10,21 & 16,00 & 5,94 & 8,75 & 10,21 \\
$\mathrm{~K}_{2}=254$ & 12,47 & 7,72 & 16,54 & 6,91 & 18,16 & 12,36 \\
$\mathrm{~K}_{3}=592$ & 7,73 & 15,72 & 12,19 & 11,62 & 11,28 & 11,71 \\
$\mathrm{~K}_{4}=850$ & 13,15 & 20,12 & 8,37 & 19,78 & 16,12 & 15,51 \\
\hline Média & 10,88 & 13,44 & 13,27 & 11,06 & 13,58 & 12,45 \\
\hline
\end{tabular}

As menores e maiores concentrações de potássio encontradas na folha a partir da combinação das lâminas com as doses de potássio foram de $5,94 \mathrm{~g} \mathrm{~kg}^{-1}\left(\mathrm{~L}_{4} \mathrm{~K}_{1}\right)$ e $20,12 \mathrm{~g} \mathrm{~kg}^{-1}\left(\mathrm{~L}_{2} \mathrm{~K}_{4}\right)$, de acordo com a Tabela 6, em que ambos os valores se encontraram abaixo do valor médio estabelecido por BORGES \& CALDAS (2003), para a cv. Pacovan, que é de $26,5 \mathrm{~g} \mathrm{~kg}^{-1}$. Um aspecto que merece 
destaque na interpretação da disponibilidade de $\mathrm{K}$ dos solos é a relação deste com os demais cátions trocáveis, principalmente $\mathrm{Ca}$ e $\mathrm{Mg}$, já que a relação entre $\mathrm{K}, \mathrm{Ca}$ e $\mathrm{Mg}$ afeta os teores do primeiro na solução do solo, pois quanto maiores os teores de $\mathrm{Ca}$ e $\mathrm{Mg}$ no solo, menor é a disponibilidade de $\mathrm{K}$ (RAIJ, 1982).

COSTA (2009) observou que as concentrações de potássio em folha no primeiro ciclo só foram influenciadas significativamente pelas lâminas de irrigação $(\mathrm{P}<0,01)$; já para o segundo ciclo, somente as doses de potássio influenciaram significativamente $(p<0,05)$ em que a maior concentração de $\mathrm{K}$ na folha foi: $35,26 \mathrm{~g} \mathrm{~kg}^{-1}$ na $\mathrm{L}_{3}$ (100\% da ETc do Lisímetro) com a dose $\mathrm{K}_{4}$ ( $200 \%$ da dose recomendada pela análise de solo) e a menor concentração foi: $25,78 \mathrm{~g} \mathrm{~kg}^{-1} \mathrm{na} \mathrm{L}_{1}$ ( $50 \%$ da ETc do Lisímetro) e com a dose $\mathrm{K}_{1}(0 \%$ de potássio).

MARCUSSI (2005), avaliando os teores de macronutrientes nos diferentes órgãos do híbrido de pimentão cv. Elisa, sob fertirrigação e ambiente protegido, constatou que, dentre os macronutrientes avaliados, o potássio foi o que apareceu com maior concentração, em todo o ciclo estudado da cultura, com média de $50,5 \mathrm{~g} \mathrm{~kg}^{-1}$ de matéria seca (do transplantio até 140 DAT). Os resultados mostraram que, em média, durante esse período, o potássio contribuiu com $38,60 \%$ da concentração total de macronutrientes. Esse resultado está acima do proposto por MALAVOLTA (1997), que é de $25 \mathrm{~g} \mathrm{~kg}^{-1}$ para a cultura do pimentão. SANDRI et al. (2006), analisando o teor de potássio na parte aérea da alface, observaram que o mesmo se mostrou adequado em todos os tratamentos, não havendo diferença significativa entre eles.

GOMES (2004) não observou diferença significativa com as doses de potássio aplicadas via fertirrigação nas concentrações de $\mathrm{K}$, na folha de bananeira, no primeiro ciclo. Porém, a ausência de resposta para as doses de potássio, possivelmente, diz respeito à população ainda não totalmente estabelecida e ainda está em fase de adaptação. Já SILVA et al. (2003) obtiveram efeitos significativos de potássio na folha de bananeira, no segundo, terceiro e quarto ciclos, na região de Minas Gerais.

\section{CONCLUSÕES}

Verificou-se que, embora o Ca e o Mg tenham sido influenciados pelas lâminas de irrigação, só foi possível estabelecer um modelo matemático para o teor de $\mathrm{Ca}$, o qual foi polinomial quadrático.

A concentração de $\mathrm{K}$ na folha aumentou linearmente com as doses de potássio, já o teor de Mg diminuiu linearmente com o potássio aplicado.

A combinação da lâmina de $1.381 \mathrm{~mm}$ sem adição de potássio $\left(\mathrm{L}_{3} \mathrm{~K}_{1}\right)$ foi a que proporcionou maiores concentrações de $\mathrm{Mg}$ e $\mathrm{S}$ na folha da bananeira. Já o teor de $\mathrm{K}$ na folha atingiu maior valor na combinação da lâmina de $1.036 \mathrm{~mm}$ com a dose de $850 \mathrm{~g} \mathrm{planta}^{-1}$ ciclo $^{-1}$.

\section{AGRADECIMENTOS}

Ao CNPq, pela concessão da bolsa de mestrado ao primeiro autor, à agroempresa FRUTACOR e ao CENTEC Limoeiro do Norte - CE.

\section{REFERÊNCIAS}

AQUINO, B. F. Adubos e adubação. Fortaleza: UFC. 2003b. 241 p. Material didático.

BATAGLIA, O.C.; DECHEN, A.R. Critérios alternativos para diagnose foliar. In: SIMPÓSIO AVANÇADO DE QUÍMICA E FERTILIDADE DO SOLO, 1., 1986, Piracicaba. Anais... Piracicaba: Fundação Cargill, 1986. p.115-136.

BORGES, A.L.; CALDAS, R.C. Teores de nutrientes nas folhas de bananeira cv. Pacovan, sob irrigação. 2003. Disponível em: <http://www.editora.ufla.br/revista/28_5/art18.PDF>. Acesso em: $1^{\mathrm{o}}$ set. 2008. 
BORGES, A.L.; SOUZA, L. da S.; ALVES, E.J. Exigências edafoclimáticas In: CORDEIRO, Z.J.M. Banana. Produção: aspectos técnicos. Brasília: EMBRAPA, 2000. p.17-23.

BRASIL, E.C.; OEIRAS, A.H.L.; MENEZES, A.J.E.A.; VELOSO, C.A.C. Desenvolvimento e produção de frutos de bananeira em resposta à adubação nitrogenada e potássica. Pesquisa Agropecuária Brasileira, Brasília, v.35, n.12, p.2.407-2.414, 2000.

COSTA, S.C. Níveis de irrigação e doses de potássio aplicados por gotejamento na cultura da bananeira para a região da Chapada do Apodi - CE. 132 f. Tese (Doutorado em Engenharia Agrícola) - Universidade Federal de Viçosa, Viçosa-MG, 2009.

DALRI, A.B.; CRUZ, R.L. Produtividade da cana-de-açúcar fertirrigada com N e K via gotejamento subsuperficial. Engenharia Agrícola, Jaboticabal, v.28, n.3, p.516-524, 2008.

DNOCS. DEPARTAMENTO NACIONAL DE ORAS CONTRA AS SECAS. Perímetro irrigado Jaguaribe-Apodi. 2006. Disponível em:

< http://20.30.148.11/ apoena/php/projetos/projetos.php>. Acesso em: 16 jan. 2007.

EMBRAPA. EMPRESA BRASILEIRA DE PESQUISA AGROPECUÁRIA. Mandioca e Fruticultura. Ministério da Agricultura, Pecuária e Abastecimento. Interação entre nutrientes em bananeira. Cruz das Almas, 2004. (Banana em Foco, 55). Disponível em:

<http://www.cnpmf.embrapa.br/publicacoes/produto_em_foco/banana_55.pdf >. Acesso em: 15 set. 2008.

GOMES, E. M. Crescimento e produção de bananeiras prata-anã e maçã fertirrigadas com potássio. 2004. 76 f. Tese (Doutorado em Irrigação e Drenagem) - Faculdade de Ciências Agronômicas, Universidade Estadual Paulista, Botucatu, 2004.

GUERRA, A.G.; ZANINI, J.R.; NATALE, W.; PAVANI, L.C. Frequência da fertirrigação da bananeira prata-anã com nitrogênio e potássio aplicados por microaspersão. Engenharia Agrícola, Jaboticabal, v.24, n.1, p.80-88, jan./abr. 2004. Disponível em:<http://www.scielo.br/pdf/eagri/ v24 n1/v24n01a10.pdf >. Acesso em: 29 out. 2009.

IBGE. INSTITUTO BRASILEIRO DE GEOGRAFIA E ESTATÍSTICA. 2007. Disponível em: $<$ http://www.ibge.gov.br/home/presidencia/noticias/noticiavisualiza.php?id_noticia=998>. Acesso em: 30 nov. 2007.

KOETZ, M.; COELHO, G.; COSTA, C.C. da; LIMA E.P.; SOUZA, R.J. de. Efeito de doses de potássio e da frequência de irrigação na produção da alface-americana em ambiente protegido. Engenharia Agrícola, Jaboticabal, v.26, n.3, p.730-737, set./dez. 2006. Disponível em: <http://www.scielo.br/pdf/eagri/v26n3/09.pdf >. Acesso em: 29 out. 2009.

MALAVOLTA, E. Elementos de nutrição mineral de plantas. São Paulo: Agronômica Ceres, 1997. $251 \mathrm{p}$.

MARCUSSI, F.F.N. Uso da fertirrigação e teores de macronutrientes em planta de pimentão. Engenharia Agrícola, Jaboticabal, v.25 n.3, set./dez. 2005. Disponível em: <http://www.scielo.br/pdf/eagri/v25n3/28059.pdf>. Acesso em: 31 out. 2009.

RAIJ, B. van. Disponibilidade de potássio em solos do Brasil. In: SIMPÓSIO SOBRE POTÁSSIO NA AGRICULTURA BRASILEIRA, 1982, Londrina. Anais... Piracicaba: Instituto da Potassa \& Fosfato, Instituto Internacional da Potassa, 1982. p.67-76.

SANDRI. D.; MATSURA. E.E.; TESTEZLAF, R. Teores de nutrientes na alface irrigada com água residuária aplicada por sistemas de irrigação Engenharia Agrícola, Jaboticabal, v.26, n.1, jan./abr. 2006.

SILVA, E. de B.; RODRIGUES, M.G.V. Levantamento nutricional dos bananais da região norte de Minas Gerais pela análise foliar. Revista Brasileira de Fruticultura, Jaboticabal, v.23, n.3, p.695698, dez. 2001. 
SILVA, J.T.A. da; BORGES, A.L.; CARVALHO, J.G.; DAMASCENO, J.E.A. Adubação com potássio e nitrogênio em três ciclos de produção da bananeira cv. Prata-Anã. Revista Brasileira de Fruticultura, Jaboticabal, v.25, n.1, p.152-155, 2003.

SILVA, J.T.A. da.; CARVALHO, J.G. de. Avaliação nutricional de bananeira prata-anã (aab), sob irrigação no semiárido do norte de Minas Gerais, pelo método DRIS. Ciência Agrotécnica, Lavras, v.29, n.4, p.731-739, 2005.

SILVA, W.L.C.; MAROUELLI, W.A. Fertirrigação de hortaliças. Irrigação \& Tecnologia Moderna, Brasília, v.52/53, 2001/2002. 